\title{
20 \\ The depiction of sensing events in English and Kalam
}

\author{
Andrew Pawley
}

\section{Introduction}

Languages are designed for talking about events and situations (for brevity's sake I will use 'event' to cover both). ${ }^{1}$ The quintessential means for constructing word-pictures of events are sentence-sized constructions in which acts, processes and states and their participants can be analytically specified - represented by words and phrases that are assigned grammatical roles, as verb, subject, direct object, etc. As the senses provide the basis of human experience of the world, it is of some interest to compare the way different languages represent sensing events and to consider explanations for the commonalities and the differences. This essay compares the way sensing events are depicted in English and in Kalam, a language of the Trans New Guinea family. Some striking differences in syntactic and semantic representations are found.

1 I am very pleased to dedicate this essay to Anna Wierzbicka, a great philosopher of language. Anna has written perceptively about understanding the senses, with reference to the semantic primitives of Natural Semantic Metalanguage (NSM), though she has not, as far as I know, focused squarely on the central concern of this chapter, which is cross-linguistic variation in ways of representing sensing events (but see Wierzbicka 1996:81-82 and 2010:78-82). For helpful comments on a draft, I am indebted to Andy Rogers, the editors and an anonymous referee. 
Neuroscientists accept the five primary senses distinguished by Aristotlesight, hearing, smell, taste and feeling by touch—but tell us that humans have other senses as well. Some, such as sensitivity to temperature and vibrations, and itching, are attributable to receptors in the skin, but others, such as awareness of balance/movement (where the body is in space), of various bodily needs and urges (hunger, thirst, needing to vomit, urinate, etc.) and of pain in an internal body part, occur by means of different receptors. For want of a better name I will refer to these other, non-primary senses as 'body internal' or 'visceral' senses.

All sensing events may be viewed as involving a stimulus or sensation (the thing that is sensed), an experiencer (a sentient being that is aware of the stimulus or sensation) and a sensing process or mechanism (the means by which the stimulus is received, e.g. by hearing, smelling, etc.). However, sensing events are otherwise quite diverse- the nature of the stimuli and the sensing mechanisms and their relation to the experiencer differ across the senses - and one might expect this diversity to be mirrored in the way different kinds of sensing events are represented linguistically.

The question arises how far the structural commonalities and differences that languages show in their representations of sensing events are predictable from common sense observations about the nature of these events. By 'common sense observations' I mean those that might be made by casual observation and reflection, without recourse to scientific study of human anatomy, physiology, perception, etc. For example, a common sense view of the mechanics of seeing is that we see things with our eyes, as opposed to the 'scientific' view that we see by using light in the visible spectrum reflected by objects in the environment, converting it into neuronal signals which travel from the retina to central ganglia in the brain.

There are many different logical possibilities for representing sensing processes linguistically. One is for each sense to be represented by a different verb, as with English see, hear, smell, taste and feel (by touch). Given that each of the five primary senses is associated with a different sensory organ - the eyes, ears, nose, mouth and skin (or body), respectivelyanother possibility is for a language to employ a single general verb of sensing, gloss it perceive and to combine this verb with the name of each of the sensory organs, yielding a set of phrasal verbs along the lines of perceive with the eyes, perceive with the ears, etc. 
Another way of distinguishing sensing processes might be to combine a verb meaning 'perceive' with a verb denoting an act that is preparatory to the achievement of perception, such as look perceive, listen perceive, sniff perceive, consume perceive and touch perceive. This makes sense, at least for tasting and feeling by touch, because normally before you taste something you put it in your mouth and start to consume it, and before you feel an object you come into bodily contact with it. It fits less well with seeing, hearing and smelling, because while these sensing processes may be preceded by an act of looking, listening or sniffing, this need not be the case. The act of perception may be accidental.

Wierzbicka $(1996,2010)$ argues for a contrast between sense concepts that are 'mental predicates' and those that are 'sensory predicates'. She regards 'see' and 'hear' as mental predicates on the grounds that we can conceive of 'seeing' and 'hearing' in a more abstract, less physical way than we can conceive of the 'sensory predicates', 'smell', 'taste' and 'touch' (Wierzbicka 1996: 82).

The five senses are different from one another in various respects. Some of them (smell, taste, and touch) refer to what a person feels in particular parts of the body. Others (sight and hearing) do not refer to any bodily feeling but to processes (seeing and hearing) which are conceptually distinct from 'feeling'. This means that the notion of 'senses' in general cannot be reduced to what a person feels in particular parts of the body (as a source of knowledge about the environment). (Wierzbicka 2010: 157)

'See' and 'hear' are accorded the status of semantic primitives, which are undefinable. The notion that 'see' and 'hear' mean to know something by means of one's eyes or ears is rejected. To accept such a definition would mean that we could not define eyes and ears via 'see' and 'hear' without circularity. She observes that of all the senses only seeing and hearing are grammaticised in the category of evidentials, reflecting their special status in human cognition.

The hypothesis that SEE is a universal semantic primitive is consistent with the view widespread across cultures that there is a special relationship between seeing and knowing, and that eyewitness evidence is more reliable than any other kind of evidence, and the hypothesized status of HEAR as universal semantic primitive tallies well with the special role of vocal speech in human communication. (Wierzbicka 1996: 81) 
I am not entirely convinced that the senses of seeing and hearing are universally viewed as more mental and less physical than the others. ${ }^{2}$ But if such a distinction is valid we might expect some languages to have distinct verbs for seeing and hearing but a single verb for smelling, tasting and feeling by touch, relying on naming the sensory organ or the stimulus to make distinctions between the latter three senses. Indeed, The Shorter Oxford English Dictionary (vol. 1: 736) records Middle English feel as meaning to perceive by smell, taste or touch.

However, various other groupings occur. Tariana, an Arawak language of Brazil, has a single verb covering both sight and hearing. The hearing sense of this verb is distinguished by taking a direct object with 'auditory' properties ('words', 'sounds', 'language', 'voice', etc.) (Aikhenvald pers. comm., cited by Wierzbicka 2010: 80). Samoan, a Polynesian language, has a single verb, lagona (with variant logo), for hearing, smelling, perceiving by taste and feeling by touch, as opposed to a verb for seeing, va'ai (Milner 1966). Hausa, a Chadic language, is reported to have one term for sight and another for the other four primary senses (Classen 1993, cited by Wierzbicka 1996: 81).

Representations of visual, hearing and smelling events might differ in the way the stimulus is viewed. Whereas one sees an object, one does not hear an object; one hears a sound. The occurrence of a sound requires a soundmaking event (someone calling, a falling tree crashing, waves splashing on rocks). It is not the source of the sound that we hear but the sound that comes from it. We can hear a call without perceiving the caller.

Smelling something is parallel to hearing in that what we smell is not an object but, in this case, an odour. One can smell an odour without being aware of its source. In the case of hearing and smelling one might conceivably represent the relation between stimulus and experiencer not in terms of the experiencer performing a sensing act (in the grammatical role of subject) but in terms of a sound or odour moving to or affecting the experiencer (in the role of direct object or dative object).

2 I readily concede that English see and hear are polysemous, having 'mental' meanings such as 'know' and 'understand' in some contexts (Do you see what I mean?, I hear what you're saying), but would argue that their primary senses belong to the domain of physical perception, by means of the eyes and ears, respectively. Smell also has mental senses. Andy Rogers (pers. comm.) suggests that if dogs could talk, perhaps smell would be taken as a mental predicate, given the efficiency and accuracy of their sense of smell. 
Let us now look at how sensing events are represented in English and Kalam. I will be concerned with the most routine or common ways of depicting sensing events in these languages, rather than with highly marked alternatives; for example, compare $I$ heard a screeching sound with the highly marked $A$ screeching sound assaulted my ears.

\section{English constructions for depicting the senses}

\subsection{Verbs of sensing}

Besides the basic sense verbs see, hear, etc. English has two other sets of verbs that refer to the senses. Let us call the three sets 'cognitive', 'active' and 'affective', after their distinct semantic functions, discussed below. ${ }^{3}$ Each set has at least five members, representing the five primary senses, though some of the same forms occur in each of the sets. Visceral feeling is represented in the cognitive and affective sets but not the active.

Table 20.1. Verbs of sensing.

\begin{tabular}{|l|l|l|}
\hline Cognitive & Active & Affective \\
\hline see & look (at) & look + adj. \\
\hline hear & listen (to) & sound + adj. \\
\hline smell & smell & smell + adj. \\
\hline taste & taste & taste + adj. \\
\hline feel (by touch) & feel & feel + adj. \\
\hline feel (viscerally) & - & feel + adj. \\
\hline
\end{tabular}

Source: Author's summary.

\subsection{Constructions with cognitive verbs of sensing}

The cognitive verbs of sensing are labelled 'cognitive' rather than 'active' because they depict an experiencer subject as being cognisant of the sensory data but are neutral with regard to intentionality. The experiencer notices the sensory data but may do so accidentally. Cognitive sensing

3 Rogers (1971), Viberg (1984) and I independently arrived at the same three-way classification of English perception verbs. I subsequently adopted two of Rogers' class labels: 'cognitive' and 'active'. I use 'affective' for the set he called 'descriptive'. Viberg's labels for the three classes are 'experience', 'activity' and 'copulative', respectively. 
events associated with the five primary senses differ from each other both in the nature of the sensory data received and with respect to the body part with which the data are received. The Macquarie Dictionary gives the following definitions: see 'to perceive with the eyes', hear 'to perceive by the ear', smell 'to perceive through the nose, inhale the odour of', taste 'to perceive or distinguish the flavour of'. Arguably, there are two feel verbs: (i) 'perceive by touch' (I felt the wind in my face) and (ii) 'become conscious of' (he felt the hot sunla surge of anger). However, a case can be made for treating (i) and (ii) as a single verb whose basic meaning is 'experience a sensation other than by sight, hearing, smell or taste'. ${ }^{4}$

The cognitive verbs of sensing can each be used as transitive verbs (see something, hear something, etc.) and as intransitives (Can you see (clearly)?, Can you hear (well)?, I can no longer smell, taste or feel).

Besides the primary cognitive sensing verbs, English has other simple and phrasal verbs that refer to perception by means of one of the senses with added information: for example, about manner, such as glimpse, (take in a) view, catch sight of, watch, overhear, catch a whiff of. There are verbs that denote awareness without specifying a particular sense, such as notice, perceive, be conscious of, and sense itself.

To depict a cognitive sensing event, English speakers commonly use an SVO (subject-verb-object) clause structure:

\section{(1) I saw a pig \\ I heard bagpipes \\ I smelt petrol \\ I tasted garlic \\ I felt something soft}

These SVO constructions are formally parallel to canonical transitive sentences such as I captured/killed/sold a pig. This is a typical example of a language economising in its range of constructions, in this case taking a construction type that prototypically depicts an actor wilfully performing an activity that affects another entity and using this construction to depict events in which an experiencer perceives a stimulus.

4 This last option is preferred in a number of English dictionaries but here I separate the two uses of feel. 
The direct object of hear and smell may be a noun phrase that refers not to a sound or odour but to an object that is the source of the sound or odour. That is, one speaks as if the experiencer hears or smells the object itself, just as one sees an object. Hear and smell can, however, also take a direct object that refers to the sound or odour or to an event that creates the sound or odour.

(2) Do you hear the sound of the bell?

Do you smell something burning?

Visceral sensory experiences can also be expressed by an SVO construction, where the sensation is represented by a noun phrase, answering the question What did $X$ feel?

(3) She felt a dull painlan itch/pangs of hungerla surge of anger/jealousy/ dizziness

However, they are often expressed by an SVAdj (subject-verb-adjective) construction, where the sensation is represented by an adjectival phrase, answering the question How did X feel?

\section{(4) She felt cold/itchy/hungry/angry/dizzy/as if she would burst}

The latter construction, with quasi-copular use of feel, shows some resemblance to one with an affective verb of sensing, discussed in section 2.4 , the difference being that in the latter the experiencer is coded as dative object whereas in (4) the experiencer is the subject.

\subsection{Constructions with active verbs of sensing}

Each of the five primary cognitive verbs of sensing has an active counterpart, in which an actor-experiencer pays attention by means of a particular sense in order to perceive. Look and listen are the active counterparts of see and hear. ${ }^{5}$ A distinction must be made between smell, taste and feel (by touch) as cognitive verbs, which are neutral with respect to intent, and the same forms as active verbs. Active verbs of sensing can all be used intransitively, without overt reference to a stimulus, and transitively, but to be made transitive look and listen require a following particle, as look at, listen to. Visceral feel does not have an active counterpart.

5 In colloquial usage, see and hear can also be used as active verbs in imperative constructions: See that man there!, Hear what she has to say! 
To depict an active sensing event directed at a target or stimulus English speakers commonly use an SVO clause structure, in which the actor is the subject and the target-stimulus is the direct object:

(5) We looked and looked at the photo but could not see the cat.

\subsection{Constructions with affective verbs of sensing}

Affective verbs of sensing, together with a modifier, refer to the impression a particular stimulus makes on the perceiver by means of a particular sense: look (appear to the eye), sound (be heard, appear to the ear), smell (give off an odour), taste (have a certain flavour), feel (have a sensation induced by touch) and visceral feel (have a sensation felt body-internally).

Affective verbs of sensing occur in dative experiencer constructions, in which the sensing experience is depicted as happening to an experiencer. The stimulus is the grammatical subject and the experiencer is the dative object, represented by an oblique case phrase introduced by the preposition to. The verb cannot stand alone $\left(^{*}\right.$ The beer tasted to me, * The cloth felt to her) but must be followed by a modifier, describing the effect associated with the stimulus. Reference to the experiencer may be omitted if it is recoverable from the context.

(6) The flowers looked beautiful (to him)

The singing sounded off key (to us)

The eggs smelled rotten (to them)

The beer tasted bitter (to me)

The cloth felt like silk (to her)

The pain felt excruciating (to me)

The affective verb serves as a quasi-copular verb, linking the subject with the adjectival predicate. Compare the use of be and seem in The flowers were beautiful (to him), The singing seemed off key (to us). 


\section{Kalam constructions for depicting sensing events}

Kalam belongs to the Madang branch of the Trans New Guinea family. ${ }^{6}$ It has upwards of 20,000 speakers, most of them living in the Simbai, Kaironk and Asai Valleys near the junction of the Bismarck and Schrader Ranges. There are two main dialects, Etp Mnm and Ti Mnm, which in morphology differ about as much as Spanish and Portuguese. Data cited here are in the Etp Mnm dialect. There is a large dictionary (Pawley and Bulmer 2011) and a fairly extensive literature on Kalam phonology, grammar, ethnobiology and social organisation. ${ }^{7}$

In grammatical structure, Kalam is a fairly typical Trans New Guinea language. Verbs carry suffixes marking person and number of subjects, and tense, aspect and mood. Inflected verbs may be dependent or independent. Dependent verbs carry a suffix indicating whether their subject is the same as or different from that of the following clause and marking tense (prior, simultaneous or prospective) relative to the next verb. Kalam has only about 130 verb roots but has a large stock of phrasal verbs consisting either of a series of verb roots or of verb adjunct + verb. Verb adjuncts are words with noun-like properties that always occur in partnership with a verb to form a complex predicate; for example, si ag (crying say) 'cry', guglum ag (snoring say) 'snore', suk ag (laughing say) 'laugh'. In canonical transitive constructions the preferred order of constituents is SOV (subject-objectverb). To depict involuntary sensations and bodily conditions much use is made of impersonal subject constructions. In these the verb is always marked for a third person singular subject, the noun phrase (NP) denoting the condition or sensation is (in at least some cases) the subject, and the experiencer is the grammatical object.

6 Trans New Guinea, containing between 350 and 500 languages, is by far the largest of the more than 20 non-Austronesian language families found in Melanesia (Palmer 2017; Pawley and Hammarstroem 2017). Trans New Guinea languages occupy most of the mountain chain that runs for more than 2,000 km east-west along the centre of New Guinea. They also dominate many of the lowland areas to the south of the central cordillera and patches of the lowlands to the north.

7 The Kalam orthography used here is phonemic but phonetically opaque. /b, d, j, g/ are prenasalised, occurring as [mb, nd, ndz, ng] word initially and medially and as [mp, nt, nt $\int$, $\mathrm{gk}$ ] word finally. / p, t, c, k/ occur as $[\phi, t, t\}, k]$ word initially, as $\left[\beta, r, t \int, y\right]$ medially and as $[b$ or $\left.p, r, t\}, k\right]$ word finally. A predictable vowel, most commonly very short [i], occurs between contiguous consonant phonemes within a phonological word, e.g. /mdp/ is [mindip], /wsb/ is [wusimp], /nnnk/ is [nininik]. The following abbreviations occur in interlinear glosses: DL dual, Ds different subject from the next verb, IMP imperative, PF perfective (today's past or present habitual), PL plural, PRIOR prior to the next verb, PROG present progressive, RP recent past, sG singular, sIM simultaneous with the next verb, ss same subject as the next verb. 


\subsection{A single verb of perception: $n \eta$}

Kalam has only one verb root denoting perception and cognition: $n \eta$. The dictionary treats $n \eta$ as highly polysemous, listing some 22 different senses, distinguishable in context. English glosses for these senses include perceive, sense, know, be aware, be awake, be conscious, notice, realise, understand, learn, see, look, hear, listen, smell, feel by touch, feel emotionally, try or test, be familiar with or used to, believe, think that (something is the case). In interlinear glosses of sentences cited below, $n \eta$ will be glossed 'perceive'-a compromise rather than an ideal gloss.

In the following sentence $n \eta$ can be understood either as an intransitive verb or as a transitive verb with direct object omitted.

$\begin{array}{ll}\text { (7) } M \tilde{n} i & n \eta \text {-sp-an? } \\ \text { now } & \text { perceive-PROG-2SG }\end{array}$

'Now do you notice/see/hear/smell/feel/understand (it)?'

In terms of the tripartite classification of English verbs of sensing outlined in section 2.1, $n \eta$ can serve both as a cognitive verb, denoting an act of perception which may be accidental, and an active verb, where an actor pays attention in order to perceive. However, $n \eta$ is not used alone as a cognitive verb meaning '(experience a) taste'. To express the experience of tasting Kalam uses a construction which depicts different kinds of taste sensations as 'acting on' the experiencer; see section 3.5). Furthermore, while $n \eta$ is commonly used as an active verb meaning 'look' or 'listen', it is not by itself used for the active senses of 'smell', 'taste' or 'feel by touch'. Each of these three active senses is represented by a lexicalised series of verb roots with $n \eta$ as the final verb.

Table 20.2. Kalam sensing verbs.

\begin{tabular}{|c|c|}
\hline Cognitive & Active \\
\hline$n \eta$ 'see' & $n \eta$ 'look (at)' \\
\hline$n \eta$ 'hear' & $n \eta$ 'listen (to)' \\
\hline$n \eta$ 'smell' & pug ny 'smell' (lit. 'sniff perceive') \\
\hline - 'taste' & $\tilde{n} b$ ny 'taste' (lit. 'consume perceive') \\
\hline$n \eta$ 'feel (by touch)' & $d n \eta$ 'feel (by touch) (lit. 'touch perceive') \\
\hline$n \eta$ 'feel (viscerally)' & - \\
\hline
\end{tabular}

Source: Author's summary. 
Although Kalam has only a single verb root for all the cognitive senses, these senses are distinguished by occurring in different syntactic constructions, which are discussed below, in sections 3.2 to 3.7 .

\subsection{Seeing}

Seeing something is expressed by a canonical transitive clause, headed by the verb $n \eta$, with the experiencer as subject and the stimulus as object. The direct object can be a minimal NP, such as a noun or pronoun, denoting the thing seen, as in (8) or a sentential NP, denoting an event, as in the second clause of (9).

(8)

Yad

1

'I saw many pigs.'

(9)

$\begin{array}{cl}\text { Ygen } & \text { tap-nonm } \\ \text { wind } & \text { substance }\end{array}$

pen ykop kawn a-nep

but just swaying precisely tree catch-RP:3SG perceive-PF-IPL

wak ak takl ap

skin the cold

$d-e-k$

$m a-n \eta-b-u n$,

not-perceive-PF-IPL

'We can't see the actual substance of the wind, but we can see it makes the trees sway when it catches them, and when the cold touches our skin we can feel it.'

Seeing can be distinguished from other senses by using the phrasal expressions $w d n n \eta$, literally 'eye perceive', and $w d n$-magi $n \eta$ 'eyeball perceive'.

$\begin{array}{rlllll}\text { (10) } T k & j a k-i, & m \tilde{n} i & n e p & w d n & n \eta-s p-i n . \\ \text { start } & \text { arise-ss:PRIOR } & \text { now } & \text { only } & \text { eye } & \text { perceive-PROG-ISG }\end{array}$ 'I've just woken up, (my) eyes are only now starting to see.' 
The body part nominal $w d n$ 'eye' or wdn-magi 'eyeball' is often accompanied by a possessive pronoun, and when combined with $n \eta$ often emphasises that someone saw something with their own eyes, rather than hearing about it from others. Another conventional expression is $w d n n \eta$ tep $g$ (lit. eye perceive well do) 'have good eyesight, see well'.

\subsection{Hearing}

Hearing something is also expressed by a canonical transitive construction, with the experiencer as subject. However, unlike seeing, to speak of hearing something minimally requires a two-clause construction, the object being expressed by a verbal clause. In Kalam you cannot simply hear a sound (I heard thunderlan explosion) or an object that is the source of a sound (I heard youla plane). You can only hear something make a sound. Soundmaking is expressed by the verb $a g$ 'make a sound, say, utter', often in combination with a noun or verb adjunct denoting a particular kind of sound (speech, calling, snoring, rattling, etc.).

(11) Nad

you

'I heard what you said.'
Yad tumuk ag-e-k
$n \eta-n-k$
I thunder say-DS:3SG-PAST
perceive-ISG-PAST

'I heard thunder.' (lit. 'I thunder sounded I heard.')
Yad kaj wa
$a g-e-k$
$n \eta-n-k$.
I pig squealing say-DS:3SG-PAST perceive-ISG-PAST
'I heard a pig squeal.' (lit. 'I pig squealed I heard')

In (12), tumuk 'thunder' is a noun and is the subject of ag. In (13) way 'squealing' is a verb adjunct, not a verb; it is always partnered by the verb ag.

A phrasal expression used to distinguish hearing from other senses is tmud $n \eta$, literally 'ear perceive'. 


\subsection{Smelling}

In Kalam one cannot speak of smelling an object. One can only smell an odour. Two alternative constructions are available for describing the smelling of an odour. Most commonly, an impersonal subject construction is used in which an odour (the subject) is depicted as 'coming to' the perceiver. To translate 'I smelled a pig' one would usually say:

$\begin{array}{llll}Y p & k a j & k u y & \text { ow-a-k. } \\ \text { me } & \text { pig } & \text { odour } & \text { come-3sG:PAST }\end{array}$

(lit. 'pig odour came to me.')

The act of perception is not mentioned but is implied. In this context ap 'come' is understood as implying 'come to the experiencer's attention'. The experiencer is represented by a pronoun or noun phrase that is grammatically an object. ${ }^{9}$

Constructions with impersonal subject are not canonical transitive constructions in that they usually show OSV (object-subject-verb) order, whereas the preferred order in canonical transitives is SOV. What shows that impersonal subject constructions are transitive is the choice of personal pronoun denoting the experiencer. Kalam has two sets of free-form personal pronouns: one marking the grammatical subject (and possessor of a noun which is the subject) and the other marking object (and possessor of a noun which is the object).

Table 20.3. Kalam personal pronouns.

\begin{tabular}{|l|l|l|}
\hline & Subject & Object \\
\hline ISG & yad & $y p$ \\
\hline 2SG & $n a d$ & $n p$ \\
\hline 3SG & $n u k$ & $n u p$ \\
\hline IDL & ctmay & ctpmay \\
\hline 2DL & $n t m a y$ & ntpmay \\
\hline 3DL & kikmay & kipmay \\
\hline IPL & $c n$ & $c n p$ \\
\hline 2PL & $n b$ & $n b p$ \\
\hline 3PL & $k i k$ & $k i p$ \\
\hline
\end{tabular}

Source: Author's summary.

8 Kalam born after about 1970 say $k i$ for $k u y . u y>i$ is a sound change in progress.

9 One might call this a dative object because the object is the receiver but in Kalam there is no formal distinction between direct objects and dative objects. 
The second option is to use an experiencer subject construction, in which the experiencer perceives an odour, as in (15) and (16). Here the first clause describes an odour as rising towards the experiencer and the second clause describes the experiencer's act of smelling it.
$M n ̃ i$
kuy
$a p \quad t a n-b$
now
odour
come
rise-PF-3SG
$n \eta-s p-a n ?$

'Now do you smell the odour coming up?'

(16)
Pakam
gutgut kuy
ak ow-pny,
$n \eta-b-a y$.
bandicoot stench odour this come-Ds:SIM perceive-PF-3PL
'When this rank odour of bandicoot comes they smell it.'

A deliberate act of smelling something is expressed by a sequence of verb roots: pug n $n$ (sniff perceive), or in the case of a dog picking up a scent and following it, pug d am ny (sniff hold go perceive). The verbs share an actor subject and take as object kuy 'odour'.
Kayn sgaw kuy ak pug $d$ am ny-sp-ay.
dog wallaby odour the sniff hold go perceive-ProG-3PL
'The dogs are following the scent of a wallaby'

\subsection{Tasting}

Experiencing a tasting sensation is depicted by an impersonal subject construction; that is, a taste happens to one. But whereas Kalam has a noun meaning 'odour, smell' it does not have a noun with the general meaning 'taste, flavour'. Instead it has a few terms for particular kinds of taste or feeling in the mouth, which serve as adjectives and, marginally, as nouns; for example, $y d k$ 'tasty, delicious, tastiness', $\mathrm{km}$ 'bitter, bitterness', slk 'pungent, spicy, hot-tasting, itchy'. These select the verb $g$ 'do, make, happen'.

$\begin{array}{cllllll}\text { (18) Yad } & k a j & a k & \tilde{n} b-e-n-k, & y p & y d k & g-a-k . \\ \text { I } & \text { pig the } & \text { eat-DS-ISG-PAST } & \text { me } & \text { tasty } & \text { do-3SG-PAST }\end{array}$ 'When I ate the pork, it tasted delicious to me.' 
(19)

$\begin{array}{llllll}\text { Snb } & \tilde{n} b-e-n, & y p & j o \eta b & \text { slk } & g-p . \\ \text { ginger } & \text { eat-DS-ISG } & \text { me } & \text { mouth } & \text { pungent } & \text { do-PF:3SG }\end{array}$ 'When I eat ginger, it gives my mouth a pungent sensation.'

Deliberate tasting is expressed by a sequence of two verbs that share an actor subject: $\tilde{n} b n \eta$ 'consume perceive' and an object, the thing consumed.

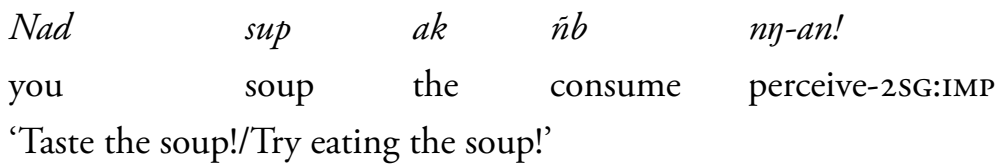

\subsection{Feeling by touch}

Experiencing a particular tactile sensation, like experiencing a taste or smell, is usually depicted as something that happens to one. Tactile sensations are represented by adjectives; for example, dlob 'slimy', deg 'slippery, smooth', gac 'dirty', kd 'sharp', kls 'firm, hard', sayn 'soft'. The verb that partners these is $g$ 'do, make, happen'. The experiencer is the object of the verb. The construction can be analysed as having a dummy subject, represented only by the third person singular subject-marking on the verb.
(21) Yad kaj wak $d \quad n \eta-e-n-k, \quad$ yp gac g-a-k.
I pig skin touch perceive-DS- me dirty do-3SG-PAST ISG-PAST

'When I touched the pig's skin, it felt dirty to me.'

However, feeling a sensation by touch can also be expressed by an experiencer subject construction headed by $n \eta$ 'perceive', as in (22) (= (9), repeated here for convenience), where $n \eta-b$-un in the final clause can be interpreted as 'we (habitually) feel (the cold)' because the preceding clause means 'the cold comes and touches the skin':

(22)

\begin{tabular}{|c|c|c|c|c|}
\hline $\begin{array}{l}\text { Ygen } \\
\text { wind }\end{array}$ & $\begin{array}{l}\text { tap-nonm } \\
\text { substance }\end{array}$ & $\begin{array}{l}m a-n \\
\text { not-p }\end{array}$ & e-PF-II & \\
\hline en $y k o p$ & $a-n e p$ & mon & $d-a b$ & $n \eta-b-u n$ \\
\hline just & swaying precisely & tree & $\begin{array}{l}\text { catch- } \\
\text { RP:3SC }\end{array}$ & $\begin{array}{l}\text { perceive-PF- } \\
\text { IPL }\end{array}$ \\
\hline
\end{tabular}




$\begin{array}{lllll}\text { wak ak takl ap } & d-e-k & n \eta-b-u n . \\ \text { skin the cold come touch-Ds: } & \text { perceive-PF-IPL } \\ & & & \text { 3SG-PAST }\end{array}$

'We can't see the actual substance of the wind, but we can see it makes the trees sway when it catches them, and when the cold touches our skin we can feel it.'

Deliberate touching, as opposed to experiencing a tactile sensation, is expressed by a sequence of two verbs sharing an actor subject: $d n \eta$ 'touch perceive'.

$\begin{array}{lllll}\text { Yad waknay } & a k & d & n \eta-n-k . \\ \text { I eel } & \text { the } & \text { touch } & \text { perceive-ISG-PAST } \\ \text { 'I felt the eel.' } & & & \end{array}$

\subsection{Body internal feelings}

Body internal or visceral feelings, with a few exceptions, are treated like sensations of smelling (option 1, see section 3.4), tasting and feeling by touch: they happen to one. The thing felt (bodily sensation, emotion, etc.) is encoded as a noun, serving as the subject, the experiencer is the object and the verb specifies the manner in which the stimulus acts on/ relates to the experiencer. The same construction is used to denote all involuntary bodily conditions, such as shivering, shuddering, hiccupping, sweating, having boils, pimples, ringworm, scabies or warts, being numb or paralysed, or feeling angry, nauseated or sleepy.

Some sensations or conditions, such as sleepiness, salivating or wanting to laugh, 'come to' the experiencer:

$\begin{array}{lll}Y p & w s n & \text { ow- } p \\ \text { me } & \text { sleep } & \text { come-PF:3sG } \\ \text { 'I feel sleepy.' } & & \end{array}$

(25) $Y p$

$$
\text { suk ow-p. }
$$

me laughter come-PF:3SG

'I feel like laughing.' 
$\begin{array}{lcc}\text { (26) } Y p & k u \tilde{k} k & o w-p . \\ \text { me } & \text { saliva } & \text { come-PF:3SG } \\ \text { 'I feel a craving (esp. for food).'I'I am salivating.' }\end{array}$

yap, yow 'fall' expresses a sensation in which something is felt to fall in the experiencer.

(27)

$\begin{array}{lll}Y p & \text { ss } & \text { yow- } p . \\ \text { me } & \text { urine } & \text { fall-PF:3sG }\end{array}$

'I feel like urinating.'

(28) $Y p$

sb yow-p.

me faeces fall-PF:3SG

'I feel like defecating.'

(29) $Y p \quad$ mluk yow-p.

me nose fall-PF:3sG

'I feel upset/annoyed.' (cf. English 'his face fell', 'his nose is out of joint.')

$g$ 'do, act, happen, make' depicts a sensation, such as shame, pain, hunger, itching, as acting on the experiencer:

(30) $Y p \quad n a b y \quad g-p$.

me shame do-PF:3sG

'I feel shame/shy.'/'I am ashamed/shy.'

(31) $Y p \quad y u w t \quad g-p$.

me pain do-PF:3SG

'I feel pain.'/'I'm in pain.'

(32) Yp yuan $g$-p.

me hunger do-PF:3SG

'I feel hungry.'/'I'm hungry.' 
(33)

$\begin{array}{lll}Y p & \text { slk } & g-p . \\ \text { me } & \text { itch } & \text { do-PF:3sG }\end{array}$

'I feel itchy.'/'I am itchy.'

$p k$ 'hit, strike, contact' occurs in a construction where the subject noun denotes a body part and $p k$ denotes a throbbing sensation:

$\begin{array}{lll}Y p & \text { jun } & p k-p . \\ \text { me } & \text { head } & \text { hit-3sG:PF } \\ \text { 'I have a headache.' } & \end{array}$

There are a very few exceptions to the generalisation that body internal sensations are depicted by impersonal subject constructions. The exceptions are cases where an internal organ (mapn 'liver', $s b$ 'bowels') is viewed as the seat of the emotions and the experiencer is cast as the subject of the verb.

$$
\begin{array}{lccc}
\text { Yad } & \text { nup } & \text { mapn } & n \eta-b-i n \\
\text { I } & \text { him } & \text { liver } & \text { perceive-PF-ISG } \\
\text { 'I feel sorry/affection for him.' }
\end{array}
$$

\section{8. 'Be like' construction}

Kalam lacks a set of affective verbs of sensing, corresponding to English look, sound, etc., where the verb plus modifier describes the impression the stimulus makes on the experiencer, as in Jane sounded elated, Jake looked as if he'd seen a ghost, Did that feel like an earthquake?

The nearest Kalam has to a functional equivalent of such a construction is an impersonal subject construction in which a noun $\mathrm{X}$ modified by the clitic tek 'like, similar, as if, seem like' combines with a verb to describe a resemblance between $\mathrm{X}$ and the subject.

$$
\begin{array}{rlll}
\text { (36) Wak } & y p & \text { mon=tek } & y n-b . \\
\text { skin } & \text { my } & \text { fire-like } & \text { burn-PF:3SG }
\end{array}
$$

'My skin feels like it's on fire.'

The verb is often $a y$ - 'become in a certain condition or state, take the form of, form, put, stabilise'. 
Sofia jomluk no-nm =tek ay-a-k.

Sofia face her-mother like form-3SG-PAST

'Sofia looks like her mother.' (lit. 'Sofia face like her mother it formed.')

(38)

$\begin{array}{llll}Y p & \text { kum-eb } & =t e k & a y-p . \\ \text { me } & \text { dying } & \text { like } & \text { form-PF:3SG }\end{array}$

'I feel as if I'm dying.' (lit. 'like dying forms me.')

However, this construction is sense-neutral: it does not say whether the resemblance is in look, sound, smell, etc.

\section{Conclusion}

It is through data provided by the senses that we perceive and construct models of the world. This applies to the linguistic modelling of sensing events themselves. We noted earlier that there are various logical possibilities for representing particular kinds of sensing events, each being compatible with common sense understandings of how these events work - of the nature of the stimuli and the sensing processes and their relation to the experiencer. One might expect this diversity to be mirrored in the syntactic and semantic representations of different kinds of sensing events across languages. This expectation is confirmed by differences in the way sensing events are depicted in English and in Kalam.

i. English has three sets of verbs of sensing with distinct semantic functions: 'cognitive', 'active' and 'affective'. Kalam distinguishes cognitive and active verbs of sensing but lacks an exact equivalent of affective verbs.

ii. English has a separate verb root for each of the five primary senses in each of the three sets. A sixth verb representing the visceral senses occurs in the cognitive and affective sets. Kalam has a single verb root, $n \eta$, which alone can refer to any of the cognitive senses with one exception: taste. To distinguish between the senses Kalam speakers specify the nature of the stimulus: one perceives (sees) a scene or object, one perceives (hears) a sound-making event, one perceives (smells) an odour and one perceives (feels) an object touched. There is no single cognitive verb of tasting. Instead, particular tasting sensations happen to the experiencer. 
iii. Kalam speakers can also distinguish between seeing and hearing by placing the term for 'eye' or 'ear' before $n \eta$, although this is only done for emphasis. This analytic strategy is available to English speakers-it is reflected in English dictionary definitions of sensing verbs that use the verb 'perceive' and identify the sensory organ and/ or the nature of the stimulus associated with each sense-but for English speakers it is a highly marked strategy.

iv. Kalam also provides a more analytic representation of active sensing verbs than English. Deliberate acts of smelling, tasting and feeling by touch are each represented by a sequence of two verb roots literally meaning, respectively, 'sniff perceive', 'consume perceive' and 'touch perceive'.

v. Another difference between the two languages concerns the handling of control or intentionality in sensing events. In English each of the six kinds of cognitive sensing events is normally represented by a canonical transitive construction, in which the experiencer appears as the subject of the verb and the stimulus as the object. Canonical transitive constructions treat the experiencer as if he/she exercises a measure of control over the sensing process. Such a uniform treatment of the cognitive senses masks differences in the degree of control that the experiencer typically has over the sensing experience.

Kalam treats seeing and hearing differently from the other senses. Whereas seeing and hearing are represented, as in English, by canonical transitive constructions, smelling and feeling by touch (as cognitive senses) are usually represented by impersonal subject constructions, in which the sensing experience is depicted as something that happens to the experiencer. Tasting and nearly all visceral sensations are always depicted by impersonal subject constructions.

vi. A further difference resides in the representation of what it is that we hear and smell. English allows us to say that we can hear an object such as a pig or a gun, whereas common sense tells us that what we hear is the sound made by the object. The interlocutor is expected to make the logical connection between object and a sound-making event. Kalam does not allow this sort of metaphor, in which an object stands for an event; it must specify the event. Similarly, English allows us to say that we smell an object whereas in Kalam one must speak of smelling an odour associated with or coming from an object. 


\section{References}

Classen, Constance (1993). Worlds of Sense: Exploring the Senses in History and across Cultures. London: Routledge.

Milner, George B. (1966). Samoan Dictionary. Samoan-English, English-Samoan. London: Oxford University Press.

Palmer, Bill (ed.) (2017). The Languages and Linguistics of the New Guinea Area: A Comprehensive Guide. Berlin: de Gruyter Mouton.

Pawley, Andrew and Ralph Bulmer (2011). A Dictionary of Kalam with Ethnographic Notes. Canberra: Pacific Linguistics.

Pawley, Andrew and Harald Hammarstroem (2017). The Trans New Guinea family. In Palmer (ed.), The Languages and Linguistics of the New Guinea Area: A Comprehensive Guide. Berlin: de Gruyter Mouton, 21-195. doi.org/ 10.1515/9783110295252-002.

Rogers, Andy (1971). Three kinds of physical perception verbs. In Papers from the Seventh Regional Meeting of the Chicago Linguistic Society. Chicago: Chicago Linguistic Society, 206-22.

The Macquarie Dictionary (2nd edn) (1991). Macquarie University: Macquarie Library Pty Ltd.

The Shorter Oxford English Dictionary on Historical Principles (3rd edn) (1944). Oxford: Clarendon Press.

Viberg, Åke (1984). The verbs of perception: A typological study. In Brian Butterworth, Bernard Comrie and Oesten Dahl (eds), Explanations for Language Universals. Berlin: Mouton de Gruyter, 123-62. doi.org/10.1515/ 9783110868555.123.

Wierzbicka, Anna (1996). Semantics: Primes and Universals. Oxford: Oxford University Press.

Wierzbicka, Anna (2010). Experience, Evidence, and Sense: The Hidden Cultural Legacy of English. New York: Oxford University Press. doi.org/10.1093/ acprof:oso/9780195368000.001.0001. 
This text is taken from Meaning, Life and Culture: In conversation with Anna Wierzbicka, edited by Helen Bromhead and Zhengdao Ye, published 2020 by ANU Press, The Australian National University,

Canberra, Australia.

doi.org/10.22459/MLC.2020.20 